\title{
Salinity-induced loss and damage to farming households in coastal Bangladesh
}

\section{Golam Rabbani*, Atiq Rahman and Khandaker Mainuddin}

Bangladesh Centre for Advanced Studies, House-10, 16A, Gulshan-1, Dhaka-1212, Bangladesh

E-mail: golam.rabbani@bcas.net

E-mail: golam.rabbani72@gmail.com

E-mail:atiq.rahman@bcas.net

Email:khandaker.mainuddin@bcas.net

*Corresponding author

\begin{abstract}
Salinity intrusion in soil caused by climate-induced hazards, especially cyclones and sea level rise (SLR), is adversely affecting rice production in coastal Bangladesh. The southwest coastal district of Satkhira is one of the most vulnerable areas because of its high exposure to salinity intrusion and widespread poverty. Based on a survey of 360 farming households in four villages and on focus group discussions, in-depth interviews and community consultations, this paper explores how salinity intrusion affects rice production. This research demonstrates that salinity levels in the soil have increased sharply over the last 20 years. The introduction of saline-tolerant rice cultivars has been the most important adaptation measure being practised. These adaptation measures, however, have not been enough to deal with the sudden increase in salinity after cyclone Aila hit the area in 2009, with devastating consequences. In that year, farmers in the study areas lost their entire potential yield of aman rice production.
\end{abstract}

Keywords: salinity intrusion; climate change; cyclone; sea level rise; SLR; loss and damage; adaptation; agriculture; rice production; coastal zone; Bangladesh; South Asia.

Reference to this paper should be made as follows: Rabbani, G., Rahman, A. and Mainuddin, K. (2013) 'Salinity-induced loss and damage to farming households in coastal Bangladesh', Int. J. Global Warming, Vol. 5, No. 4, pp.400-415.

Biographical notes: Golam Rabbani is a Senior Researcher at the Bangladesh Centre for Advanced Studies and has an academic background in environmental science and risk assessment. He has been working on environment and climate change issues at national and regional levels for about ten years, mainly in the areas of climate risk and vulnerability assessment, risk management and adaptation to climate change, and policy and institutional arrangements. His contribution to research work has been well acknowledged through both national and international publications. His articles related to climate change have recently been published by Springer, Routledge, Earthscan, Environment and Urbanization, and Emeralds. He is also involved in climate negotiation. 
Atiq Rahman is the Executive Director of Bangladesh Centre for Advanced Studies (BCAS). He is a well recognised Global Leader in Sustainable Development. He was a lead author of the IPCC Fourth Assessment Report. He was awarded the highest UN award on Environment the 'Champion of the Earth 2008' by the UNEP for the Asia Pacific Region. The UN citation states that the award is given for his 'extraordinary leadership and contribution to environmental issues, sustainable development and climate change'.

Khandaker Mainuddin is a Senior Fellow at Bangladesh Centre for Advanced Studies. He has over 30 years of professional experience in research/impact assessment studies. He has been a team leader, coordinator and member of expert groups for different studies/research project in several fields including climate change, poverty alleviation, disaster management, agriculture, fisheries and environment.

This paper is a revised and expanded version of a paper entitled 'Salinity induced loss and damage on rice production in selected coastal district of Bangladesh' presented at United Nations University Scientific Conference: 'Perspectives on Loss and Damage: Society, Climate Change, and Decision Making', Bonn, Germany, 25-28 February, 2013.

\section{Introduction}

The people of Bangladesh, especially in the coastal zone, are struggling with the adverse impacts of climate change. The major hazards related to climate change include: variations in temperature and rainfall, drought, cyclone and storm surges, and salinity intrusion. These are affecting almost all sectors and sub-sectors across the country, including rice production. Rice is the principal crop and staple food of Bangladesh.

Loss and damage associated with climate change and climate variability is an emerging concept in climate change research and in the global negotiation process. The concept of 'loss and damage' has been discussed by many international organisations and scientists but still there is no agreed definition under the United National Framework Convention on Climate Change (UNFCCC). This paper refers to the proposed definition of loss and damage, which is: "Loss and damage refers to negative effects of climate variability and climate change that people have not been able to cope with or adapt to" (Warner et al., 2012).

This paper is composed of four sections. Section 1 presents a very brief overview of the major climate change events affecting the coastal zone of Bangladesh, the concept of loss and damage and a short description of the case study area (Figure 1). Section 2 describes the tools and techniques used to collect field data. Section 3 discusses salinity levels in the soil and associated impacts, current adaptation practices, an estimation of loss and damage in the study villages, and potential adaptation measures. Section 4 comprises concluding remarks.

The coastal zone is extremely vulnerable to a number of rapid- and slow-onset events that affect rice production and related livelihoods. Currently, cyclones accompanied by storm surge and increased salinity intrusion into fresh water and soils are the most catastrophic phenomena for coastal communities, especially in Satkhira, a vulnerable coastal district. At least nine major cyclones have hit the coast in the last 50 years. But in 
the last decade, the number of cyclonic events from the Bay of Bengal has increased. Cyclone Sidr in 2007, cyclones Nargis and Reshmi in 2008 and cyclone Aila in 2009 caused huge damage in Bangladesh and Myanmar. The government of Bangladesh estimates that the total cost of damage from cyclone Sidr was US\$1.6 billion (DMB, 2010). Cyclone Sidr killed more than 3,000 people; it also directly affected about five million families and crops of about 0.7 million hectares (Rabbani et al, 2010; DMB, 2010). According to the Bangladesh Bureau of Statistics (BBS), cyclone Sidr caused damage to more than 0.1 million tons of rice crop in Khulna (one of the most affected 12 coastal districts) (BBS, 2009). Cyclone and storm surges induced by climate change force saline water into agricultural lands along the coast, which damages crops not only in the year the cyclone hits, but for several years afterwards. This has also happened in the area that was studied for the present research, Shyamnagar Upazilla in Satkhira district. Saline water intrusion caused by cyclone Aila in 2009 led to loss and damage to rice crops in many villages in the area. Some recent studies indicate that salinity intrusion in both soil and water might increase further because of escalating intensity of cyclone and storm surge (Ministry of Environment and Forests, 2005; Rabbani et al., 2010; SRDI, 2010).

Figure 1 The study unions (Ramjannagar and Munshiganj) in Shyamnagar Upazilla, Satkhira district (see online version for colours)

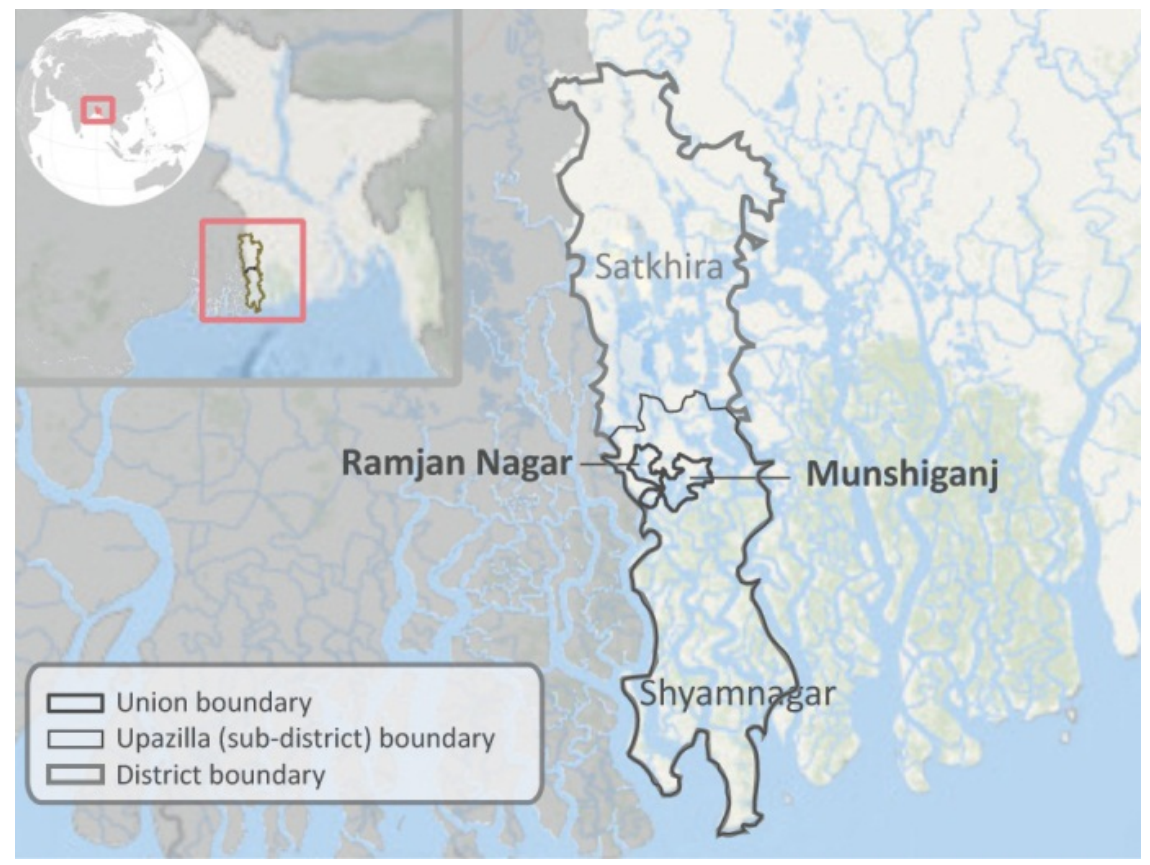

In order to understand the interaction of salinity intrusion and rice production, how people are adapting and whether adaptation measures are enough to avoid adverse climate-change impacts, a study was conducted in four villages within two unions ${ }^{1}$ at Shyamnagar Upazilla (sub-district) in Satkhira District. Satkhira is an exposed coastal district in the southwest region in the Khulna division of Bangladesh. The district covers $3,858 \mathrm{~km}^{2}$ and the population is roughly 2.2 million (BBS, 2008). The district has 78 
unions under seven sub-districts (upazilla in Bengali) including Shyamnagar. The main rivers are Kobadak, Sonai, Kholpatua and Kalindi-Jamuna. Most of the rivers are tributaries of the Ganges, which flows into the Bay of Bengal. The most common livelihoods are in agriculture, fishing, pisciculture, etc. (Banglapedia, 2003). The main crops of Satkhira District are rice $\left(a u s,{ }^{2} a a_{n}{ }^{3}\right.$ and boro $\left.^{4}\right)$, wheat, jute, sugarcane and vegetables. The district has a hot summer from mid-March to early June, and a mild winter between late November and mid-February. Out of seven sub-districts, Shyamnagar is the largest, with an area of about $2,000 \mathrm{~km}^{2}$ (more than $50 \%$ of Satkhira). At least $75 \%$ of Shyamnagar lies under the area of Sundarban (BBS, 2008). The study locations were Jelekhali and Kultoli villages, in Munishiganj Union, and Patarakhola and Tengrakhali in Ramjannagar Union in Shymnagar Upazilla of Satkhira.

Figure 2 Cyclone Aila affecting the study area in May 2009 (see online version for colours)
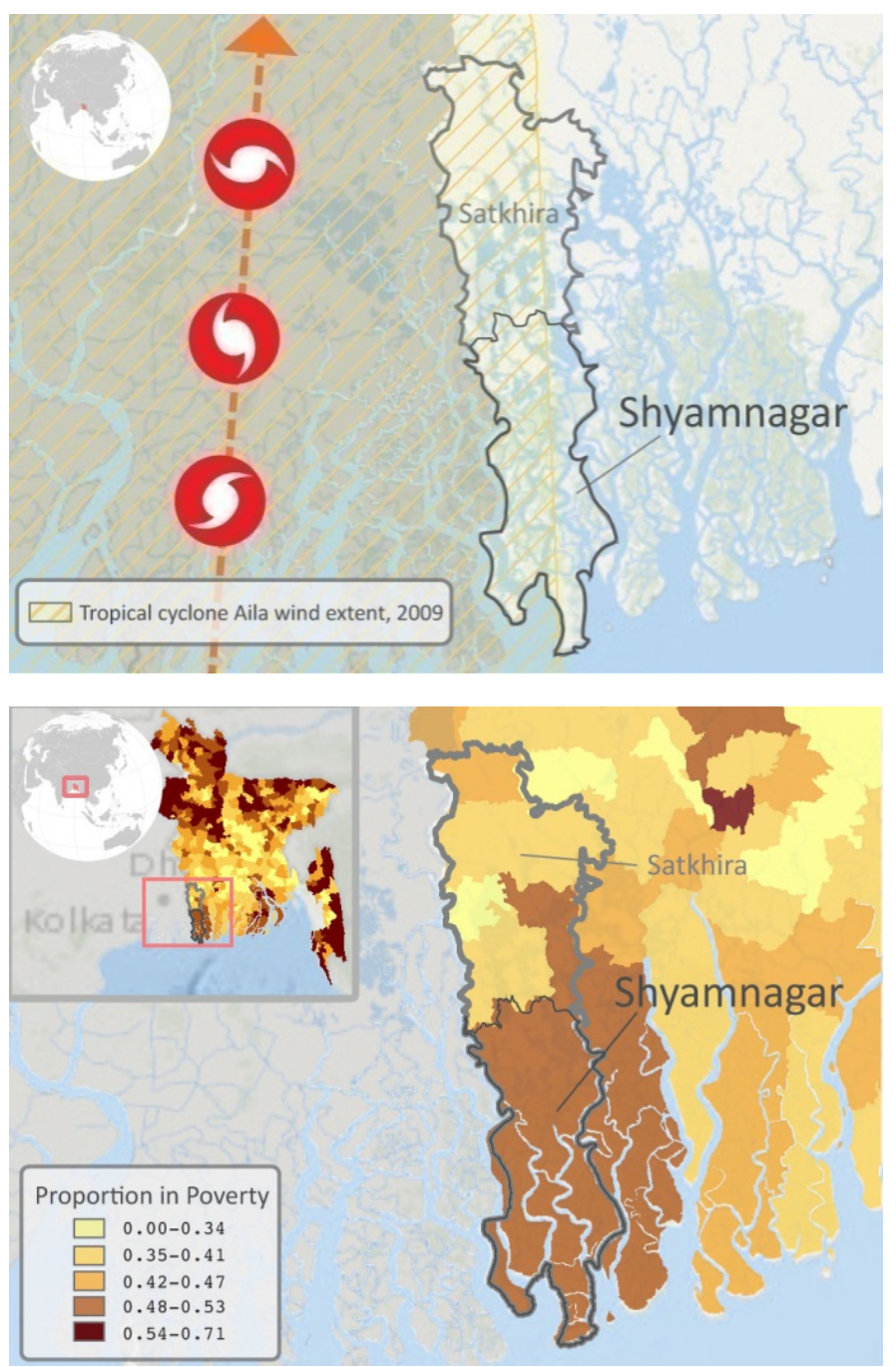


\section{Materials and methods}

Both quantitative (household survey) and qualitative tools (focus group discussions, in-depth interviews and community consultations) were used to explore the impacts of salinity intrusion on rice production in the study villages. The survey targeted 360 farming households in two villages in each of the two unions in Shyamnagar Upazilla, Satkhira district; the sample size for each of the four villages was 90. Households were selected by a systematic random sampling procedure for each of the villages. The survey questionnaire was designed to capture relevant data and information from the study villages. It covered the socio-economic profile of study households, awareness and understanding of climate change and salinity problems, perceptions of the history of salinity levels, the impact on rice production of salinity intrusion caused by extreme weather events, adaptation measures, and loss and damage in rice production. In addition, village representatives provided and validated the data/information gathered in focus group discussions and interviews conducted in each of the study villages. Findings from focus group discussions and interviews were also scrutinised in community consultation meetings. Secondary data and literature were reviewed to complement the primary data gathered during the fieldwork. This case study was part of a larger research project - the Loss and Damage in Vulnerable Countries Initiative. The methods for conducting case studies for this project are described in more detail in Warner et al. (2012). A systematic research protocol was followed to avoid possible bias. The study villages were selected based on a pre-survey field visit and in consultation with local government institutes and vulnerable communities. The villages selected were those most affected in the study sub-district. The survey questionnaire was developed in a peer-review process to ensure it was consistent with the subject and local issues, was translated into Bengali (the local language) and was pre-tested. The data collectors were trained for the interview with farming households in the study areas. Moreover, the field team for each village had at least one member from the Satkhira region, which helped with communicating appropriate questions and responses during the interviews and focus group discussions. The qualitative tools, including focus group discussions and community consultation, helped to gather details on the subject and verify responses from the survey. Suitable participants for the focus group discussions were identified from the household survey. Three members of the field team conducted the focus group discussions. One team member presented the issues and questions for discussion and the responses; the others recorded the discussion points. The key findings of the focus group discussions were presented to the key study representatives of the four villages. This also helped to validate the findings.

\section{Results and discussion}

\subsection{Study areas, population and socio-demographic settings}

As mentioned above, the study was conducted in four villages (Jelekhali, Kultoli, Patarakhola and Tengrakhali) in Shyamnagar Upazilla in Satkhira district. Of the 360 participants in the study, 69\% were men and 31\% women. Participants were relatively young to middle aged, with about $50 \%$ (both male and female) between the ages of 20 and 40 ; about $24 \%$ were over 50 years of age. Nearly $24 \%$ of respondents had completed 
primary education (Class 1-V), 26\% had completed junior education (Class VI-X) and $11 \%$ had had a university education. It was found that $26 \%$ of respondents know how to write their name only, while $13 \%$ were totally illiterate. The main occupation in the study villages was agriculture farming; $81 \%$ of respondents were involved with agriculture farming as their main occupation. The most significant sources of income for the study households were: rice cultivation (98\%), livestock rearing (94\%) and economic trees ${ }^{5}$ $(88 \%)$. Other income was from fishing $(56 \%)$, farm labour $(39 \%)$, non-agricultural activities $(65 \%)$, remittances $(8 \%)$ and other sources $(7 \%)$.

The study indicates that $28 \%$ of the total income in the study areas comes from the rice cultivation. The study also found that the annual average income per household among the study population is US\$1,335. This makes the per capita income of the study population US\$303 $(1,335 / 4.4)$, which is $64 \%$ lower than the national per capita income. Thus, poverty remains one of the major factors pushing local communities towards greatest vulnerability to extreme events.

\subsection{History and trend of rice production and salinity}

Islam (2004) states that many coastal districts, including Satkhira, are facing increased levels of salinity in agricultural fields. A recent report shows that more than 1 million hectares of arable land in Bangladesh are affected by salinity intrusion caused by slow- and rapid-onset events (SRDI, 2010). It also points out that $71 \%$ of cultivated areas in Shyamnagar Upazilla are affected by high-level salinity (above $12 \mathrm{dS} / \mathrm{m}$ ). According to the BBS, the net cultivated area in Satkhira decreased by about 7\% from 1996 to 2008 (BBS, 2008). It was found that immediately after cyclone Aila, total rice production in Satkhira decreased from 0.53 million tons in 2008 to 0.46 million tons in 2009 (BBS, 2009,2010 ). The report also indicates that production of the principal rice crop (aman rice) in Satkhira decreased substantially, from about 0.3 million tons in 2008 to 0.2 million tons in 2010.

The Ministry of Environment and Forests (2005) predicts that a sea level rise (SLR) of $14 \mathrm{~cm}, 32 \mathrm{~cm}$ and $88 \mathrm{~cm}$ will affect Bangladesh by 2030, 2050 and 2100 respectively. The predicted SLR is expected to push saline water further inland and affect not only rice production but also all other agricultural practices in the future. A recent estimate is that the country may lose 0.2 million tons of crops to saline intrusion in a moderate climate scenario, but that this might be more than double in a severe climate scenario (Huq and Ayers, 2008).

\subsection{Community perception of salinity levels in rice fields}

Focus group participants and questionnaire respondents claim that salinity intrusion has increased sharply over the last decade and particularly over the past five years (see Figure 3). Current high salinity in rice fields is caused to a large extent by cyclone Aila, which hit the area in 2009. In 2012, when the fieldwork took place, more than $80 \%$ of farming households experienced high salinity in rice fields, compared to $2 \%$ and $13 \%$ ten and five years ago respectively (Figure 3 ). The proportion of salinity-free farmland has gone down over the past 20 years, from more than $60 \%$ to nil. Almost all saline-free and low-salinity farmland has turned into medium- or high-salinity farmland, which has a severe impact on agricultural productivity. 
Figure 3 Respondents' perceptions of trend of salinity during last 20 years in the study area, by percentage (see online version for colours)

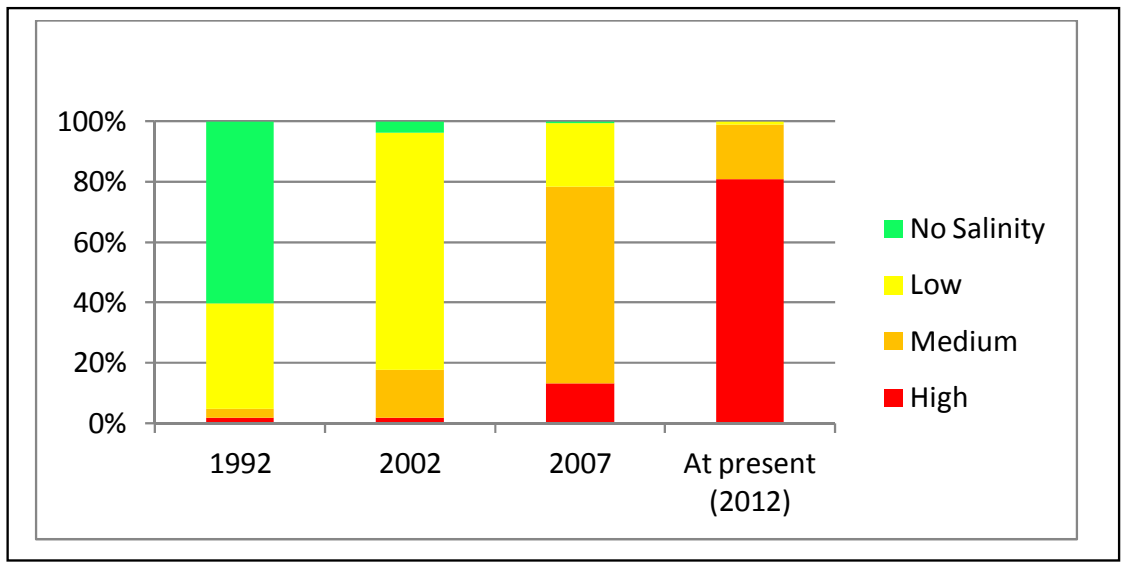

A comparison of survey results from the four study villages shows that although the level of salinity in rice fields has varied from village to village over the last 20 years, the trends are the same: ever-increasing salinity (see Figures 3 and 4). Tengrakhali is currently the most adversely affected village, as noted by more than $90 \%$ of respondents; salinity level has increased from $36 \%$ to over $90 \%$ in this village in the last five years. The other three villages have been affected by high salinity mainly in last five years. Jelekhali village seems to be the least affected (Figure 4).

Figure 4 Respondents' views on distribution of 'high' level of salinity in four villages in last 20 years (see online version for colours)

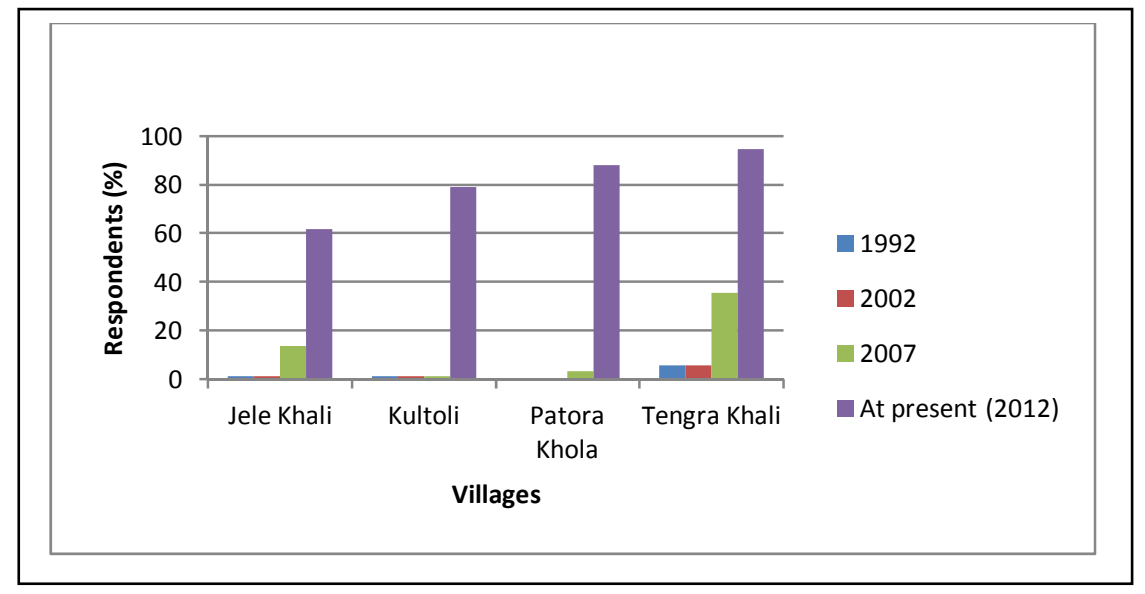

\subsection{Impacts and evidence}

Farmers in the Shyamnagar study villages mainly cultivate aman rice varieties, which grow between April and August. In the past 20 years, the pattern of aman production in 
Ramjanagar Union has been quite irregular. The data show that total aman production was more than 8,500 tons between 1993 and 1997, but was less than 8,000 tons from 1998 to 2006, except in 2002 when it was 8,460 tons. In 2008, the production of aman was about 6,800 tons. Since then, it has decreased substantially by $31 \%$ and $15 \%$ in 2009 and 2010 respectively in the study union (UAO, 2012). According to UAO data, a similar pattern was observed in the other study union, Munshiganj - although in group discussions and community consultations farmers mentioned that all four study villages in both the abovementioned unions had 'zero production' of rice in 2009, immediately after cyclone Aila hit. More specifically, the yield of the aman crop has shifted from an average of 2.9 tons per hectare in 2008 to 0 tons per hectare in 2009 in all the study villages due to high salinity in the rice fields, as reported by local farmers. In the year after Aila (2010), some farmers in the study villages tried aman cultivation again, despite high salinity levels, but their yields were less than 1 ton per hectare. In 2011, farmers in all four villages were able to slightly increase their aman yields to an average of 1.3 ton/ha. However, the yield was less than $50 \%$ of that of 2008 (the year before cyclone Aila). It may be worth mentioning that rice production data provided by study area farmers may be more reliable. In addition, most impacted villages were selected to explore interactions between salinity intrusion and rice productions.

There were various responses regarding the changes in rice production over the last 20 years. About $76 \%$ of farmers in the study villages believed rice production has decreased over the years. More than half of the respondents $(55 \%)$ mentioned that rice production had 'decreased a lot' over the last 20 years: the highest $(82 \%)$ was in Patarakhola and the lowest $(41 \%)$ in Kultoli. This significant decrease in Kultoli and Patarakhola is fairly consistent with high levels of salinity in rice fields in both villages, as mentioned above. On the other hand, at least $11 \%$ of farmers claimed that rice production increased a lot over the years: the highest $(24 \%)$ was in Kultoli and the lowest $(2 \%)$ in Patarakhola.

Figure 5 Change in rice production in the study areas over the last 20 years (see online version for colours)

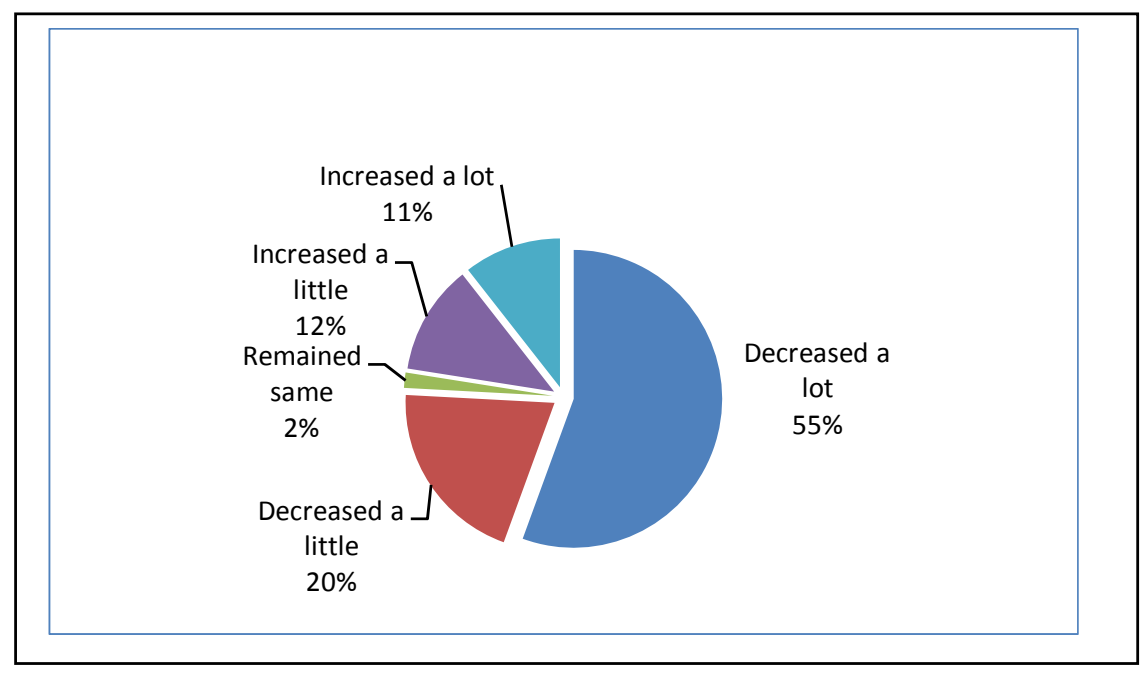


Changes in rice production cause food crises in the study villages. A majority $(63 \%)$ of the study households were found to be facing a food crisis at some time of the year. Figure 6 shows that the study population faces a food crisis that varies from month to month, with peaks in September and October. These are the later months of the monsoon, just before the harvesting of aman rice. During the winter months (December to February) study households experience less food shortages. The study finds that households in Ramjannagar Union (Tengrakhali and Patarakhola villages) experience slightly more food shortages compared to households in Munshiganj Union (Jelekhali and Kultoli villages). On average, $69 \%$ of households in Ramjannagar Union face a food crisis in October, while in Munshiganj Union the figure is $67 \%$. In group discussions and consultation meetings, it was explained that the food crisis in the study villages of Ramjannagar Union is much worse than in Munshiganj, although the survey finding does not adequately reflect that.

Figure 6 Percentage of respondents facing food crisis during different months of the year (see online version for colours)

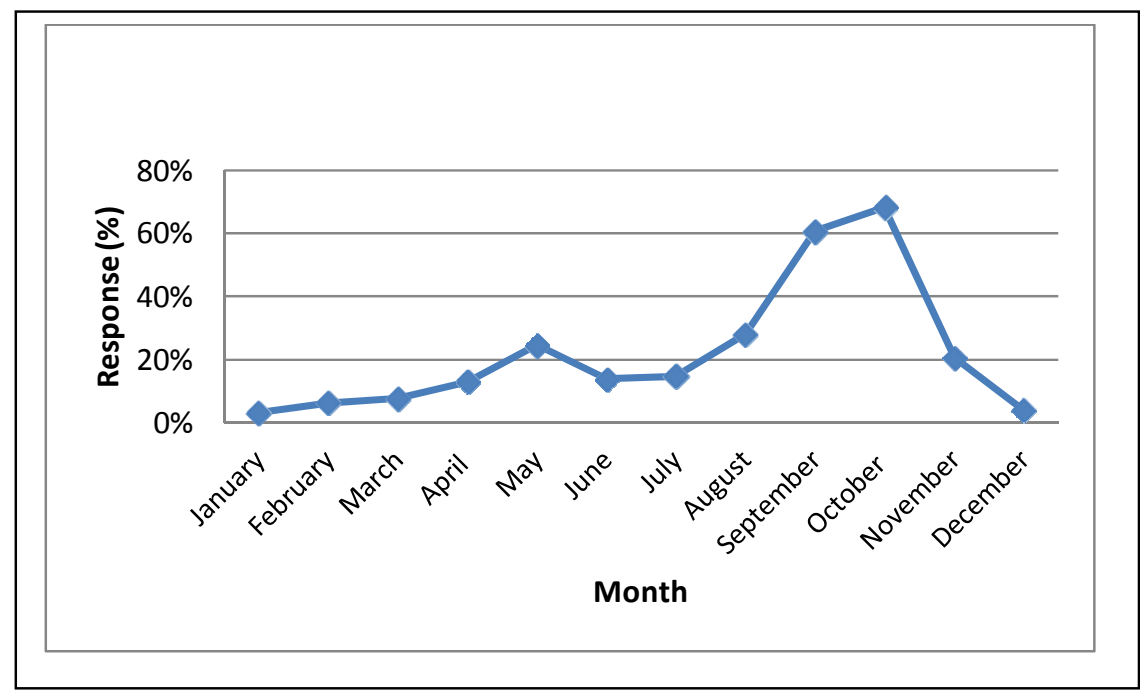

In group discussions and interviews, participants explained that the impacts of salinity intrusion affect men and women differently, mainly because of the level of exposure and different roles men and women play in the household. For example, one male respondent said, "I am losing rice and vegetable production due to salinity intrusion in the agricultural fields, which is directly affecting my income", while a woman respondent reported, "I have to walk at least $1.5 \mathrm{~km}$ every day, especially during pre-monsoon (March-April-May) and winter (December-January-February) season, to collect water for drinking from the nearest pond/PSF (pond sand filter) in which the salinity tastes low."

\subsection{Salinity intrusion is the main cause of declining rice production in the study areas}

Figure 5 showed that $75 \%$ of respondents reported declining rice production. Figure 7 indicates the main reasons given for declining rice production. Most respondents (96\%) 
identified salinity intrusion as the main cause of declining rice production, followed by lack of rainfall $(73 \%)$. Other factors mentioned included excessive rainfall in short periods of time (called 'sky floods' locally), pest attack, not having fertiliser at the right time, water logging, high cost of cultivation, and lack of irrigation water. The group of $23 \%$ who reported increasing rice production consisted mainly of relatively rich farmers who were able to invest in improved technology, fertilisers, improved seeds and others external inputs. Other farmers who were able to increase rice production had land with low salinity, sufficient fresh water for irrigation, and access to saline-tolerant rice varieties. All the farmers strongly believed that salinity intrusion in soil and water is the main challenge to rice farming in the study areas.

Figure 7 Percentage of respondents on causes of reduction in rice production (see online version for colours)

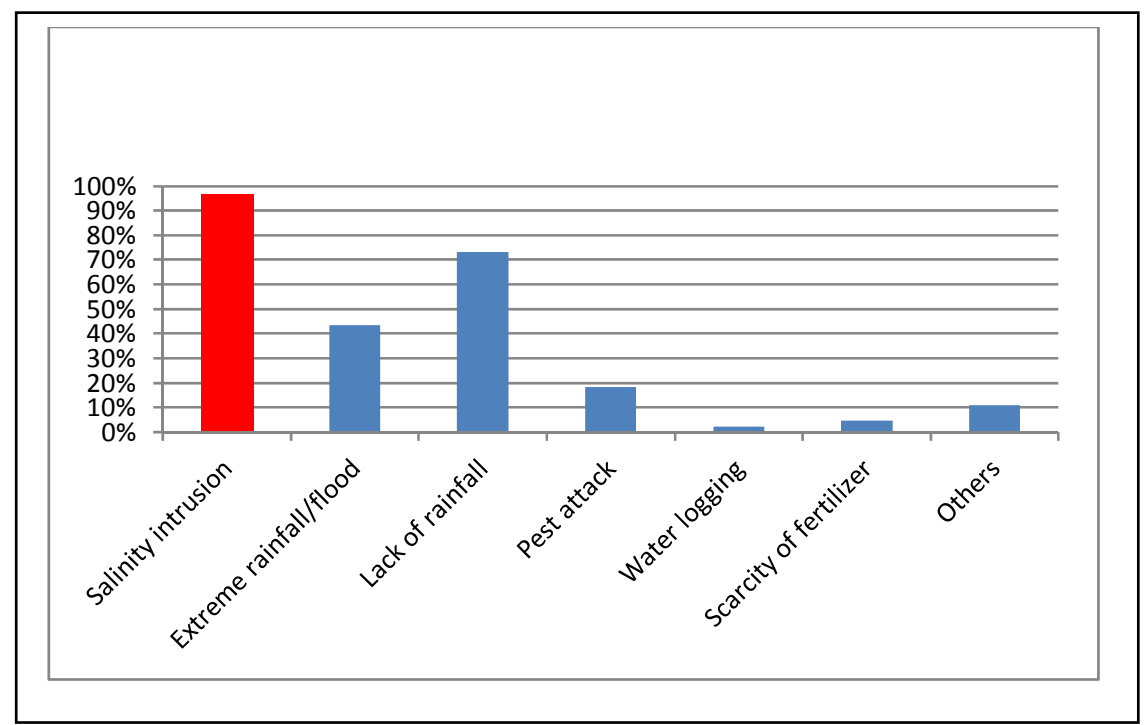

\subsection{Existing adaptation measures}

To deal with salinity intrusion and associated impacts, farmers in the study area have adopted a number of non-field and field-based adaptation measures. Field-based measures are mainly aimed at reducing the impact of salinity intrusion on agricultural production. Non-field-based measures aim to make livelihoods less dependent on farming. Field-based measures ${ }^{6}$ mainly include using saline-resistant cultivars, reducing salinity by washing rice fields, adjusting irrigation practices, and repairing or reconstructing irrigation channels. Non-field measures ${ }^{7}$ include temporary migration for work (either within the home district or to another nearby district), changing eating habits and lifestyles, switching to non-agricultural income-generation activities, etc.

The study found that $61 \%$ of households adopted some field-based (rice fields) adaptation measures; of these, 39\% planted saline-resistant cultivars (BRRI 23, BRRI 47, BINA-8) (Figure 8). One would expect these measures to be most widespread in Tengrakhali, where salinity was highest. In reality, only $40 \%$ of households in Tengrakhali village implemented saline-resistant cultivars, whereas about $57 \%$ of 
households in Kultoli village had done so. It was clear from discussions with study households that awareness of the impact of salinity, access to saline-resistant cultivars, poverty and local knowledge about measures to combat salinity all play a vital role in whether adaptation measures are implemented. This might account for the fact that Jelekhali and Kultoli villages (Munshiganj Union) are more successful than Patarakhola and Tengrakhali villages (Ramjannagar Union) in terms of field-based adaptation. Although many households $(27 \%)$ washed rice fields at different stages of cultivation to reduce soil salinity, planting saline-resistant cultivars remains the most common adaptation measure to increasing salinity in the study areas.

Figure 8 Existing adaptation measures to deal salinity intrusion in rice fields (see online version for colours)

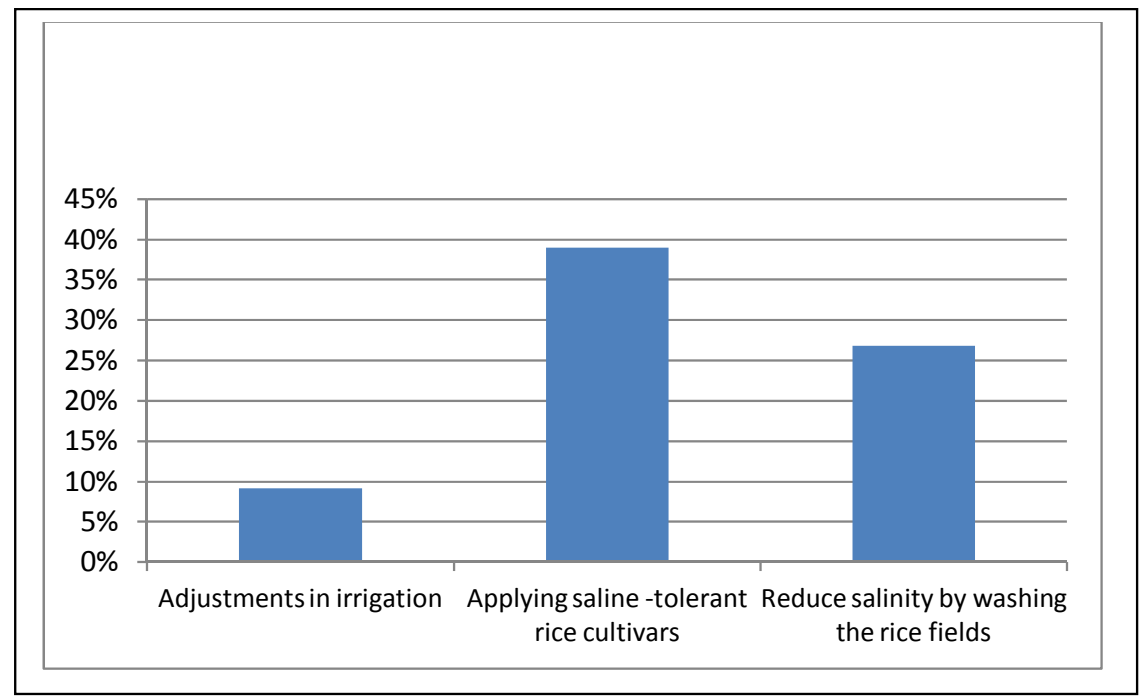

Of non-field adaptation measures, the study indicates that more than $70 \%$ households take out loans, reduce household expenses and change eating habits to cope with the impact of salinity on rice production. Table 1 shows that $55 \%$ of households try to earn more to overcome the crisis situation, while about $30 \%$ migrate to find work elsewhere. Many male members of the households studied migrate temporarily to work, either to the nearest district or to Dhaka, the capital city. Some households have migrated permanently, as confirmed during focus group discussions and interviews. In Tengrakhali village, non-field adaptation measures are very prominent compared to practices in other study villages. The study population in Tengrakhali were found to be the most likely to adopt most of the non-field adaptation measures - including taking out loans, reducing household expenditure, changing food habits and switching to non-farm activities, e.g., rickshaw/van pulling, selling dry food in the nearest market, etc (see Table 1). It should be noted that Tengrakhali is a very remote village, with higher poverty and lower education levels compared to Jelekhali and Kultoli villages. The remote villages traditionally lack infrastructure and face challenges in accessing up-to-date information, technology, etc. 
Table 1 Existing coping/adaptation measures (non-field) to deal with overall impact of salinity intrusion on rice production in the study areas in Shyamnagar, Satkhira

\begin{tabular}{|c|c|c|c|c|c|}
\hline \multirow{2}{*}{$\begin{array}{l}\text { Existing coping/adaptation } \\
\text { measures (non-field) }\end{array}$} & \multicolumn{4}{|c|}{ Villages in the study area } & \multirow{2}{*}{ All } \\
\hline & Jelekhali & Kultoli & Patarakhola & Tengrakhali & \\
\hline $\begin{array}{l}\text { Taking out loans from } \\
\text { non-governmental organisations, } \\
\text { neighbours, relatives }\end{array}$ & 66.29 & 68.89 & 75.82 & 78.89 & 72.50 \\
\hline $\begin{array}{l}\text { Trying to earn more by } \\
\text { increasing working hours }\end{array}$ & 48.31 & 52.22 & 47.25 & 72.22 & 55.00 \\
\hline Migration & 17.98 & 52.22 & 8.79 & 40.00 & 29.72 \\
\hline Selling household assets & 32.58 & 23.33 & 9.89 & 24.44 & 22.50 \\
\hline Cutting household expenditure & 67.42 & 68.89 & 69.23 & 83.33 & 72.22 \\
\hline Changing eating habits & 59.55 & 65.56 & 63.74 & 93.33 & 70.56 \\
\hline Switching to non-farm activities & 13.16 & 21.43 & 19.23 & 34.72 & 25.00 \\
\hline
\end{tabular}

\subsection{Perception of the effectiveness of adaptation measures in the study areas}

Field-based adaptation measures (e.g., saline-resistant cultivars, washing rice fields, raising seed beds, adjustments to irrigation, etc) were not adequate to address salinity risks. Most (64\%) of the households who adopted the abovementioned measures reported that they did not adequately cope with the impacts of salinity intrusion; only $15 \%$ said the measures were effective. On the other hand, $39 \%$ of the study households did not implement any adaptive measures for rice cultivation. Most of these households cited lack of knowledge about salinity effects, lack of access to saline-resistant cultivars, poverty, etc as reasons for not implementing adaptation measures.

\subsection{Estimated loss and damage caused by salinity intrusion}

Current coping mechanisms are not sufficient to cope with increased levels of salinity caused particularly by the extreme weather events of 2009. Poverty, low-level resilience, and lack of alternative livelihoods, together with climate-induced hazards, are responsible for huge losses, not only for the villages studied but also for communities along the whole coast.

The study estimated aman rice production loss using 2008 as the base year. Figure 9 shows the cost of loss of rice production due to salinity intrusion caused by cyclone Aila for three consecutive years in the study villages. It appears that the total cost of loss was US\$1.9 million for three years in the study villages. This estimate was based on data on aman rice production and farm gate prices for 2008 provided by the farmers in group discussions in the presence of farmers and local agriculture officers. This estimate was further scrutinised and validated in the presence of representatives of at least $20 \%$ of surveyed households from each of the study villages and local government agriculture officers. As mentioned at the beginning of Section 3, none of the study villages had had a rice crop in 2009. Therefore, the highest loss (US\$0.76 m) was incurred in 2009, followed by US $\$ 0.72 \mathrm{~m}$ in 2010 (loss of 94\%, compared to base year) and US\$0.42 $\mathrm{m}$ in 2011. 
Figure 9 Cost of loss of rice production due to salinity intrusion caused by extreme event (cyclone Aila) in four study villages (US\$ million) (see online version for colours)

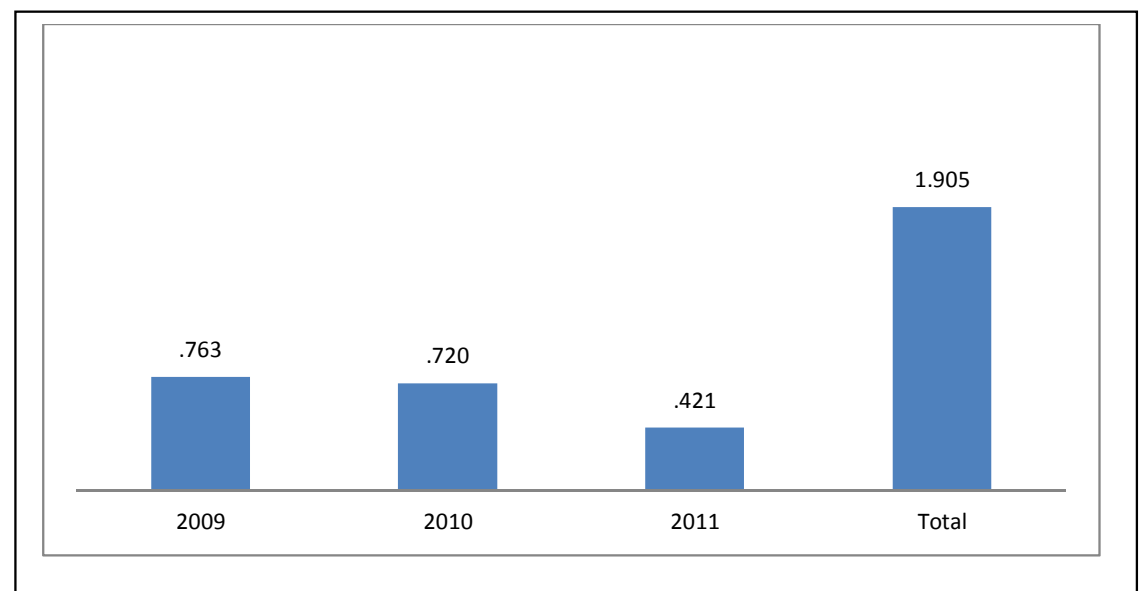

Figure 10 Value of loss (as \% of household annual income) due to decrease in rice production caused by cyclone Aila-induced saline intrusion, by income group (see online version for colours)

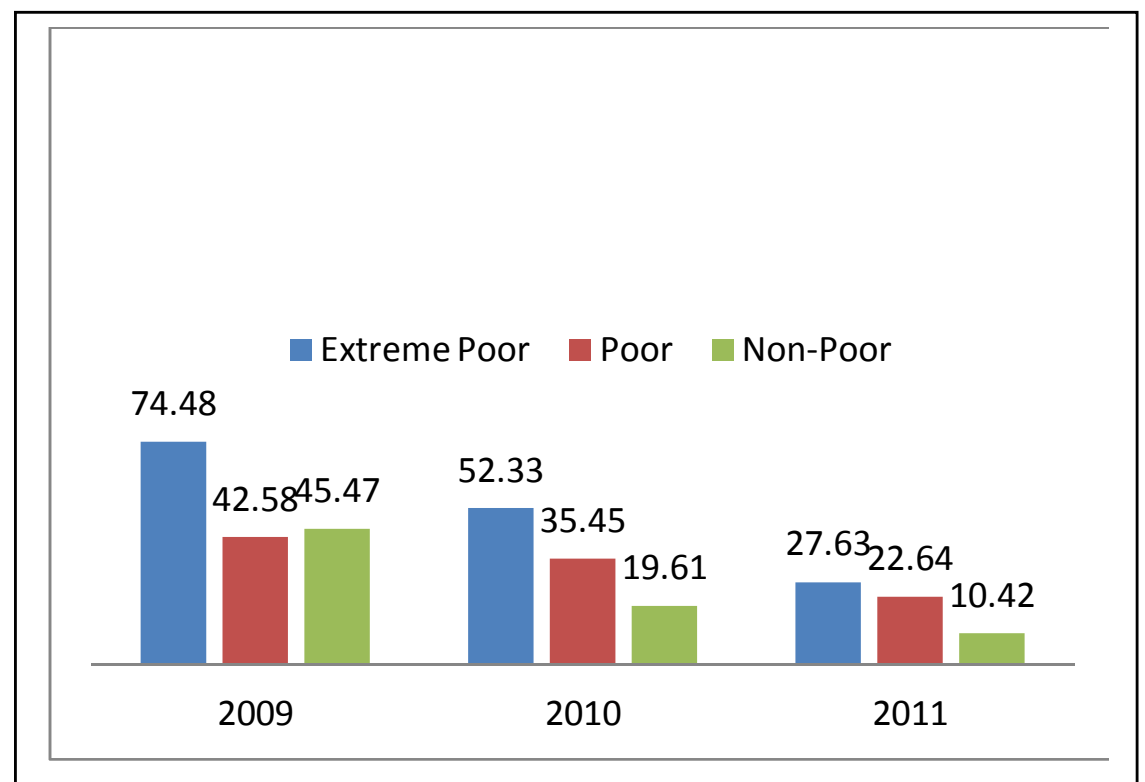

The survey found that almost all the households in the study area incurred losses in rice production due to salinity intrusion, especially caused by cyclone Aila in 2009. The average loss per household was US\$2,021 in 2009 for the complete loss of aman rice crop. In addition, on average, each of the sampled households had to spend US\$34 for reconstructing or repairing irrigation systems, US\$32 for washing rice fields to reduce salinity, US\$41 for repairing seed beds and US\$7 for buying drinking water in the same 
year. Moreover, on average, each affected source of water (e.g., ponds, tube-wells, etc) incurred costs of US\$220 (on average) for cleaning or repairing.

The study also indicated that loss and damage associated with salinity intrusion in rice production affects income groups (extreme poor, poor and non-poor) differently. The income of extremely poor households from rice cultivation was affected most. In 2009, the loss incurred by the extreme poor was about $74 \%$ of their last annual household income, whereas other households lost $43-45 \%$ of their last annual income. In addition, from 2009 to 2011, all the sampled households were gradually adapting in some way to reduce loss in rice production. But the poor and extreme poor households were recovering their situation at a slower rate than non-poor households.

\section{Conclusions}

Climate change, including salinity intrusion caused by extreme events (e.g., cyclone and storm surge) and slow-onset events (e.g., SLR) are leading to negative impacts on almost every economic sector in Bangladesh, including agriculture. Cyclones Sidr (2007) and Aila (2009) had a devastating effect on rice cultivation in Satkhira District, including in the four villages in which fieldwork for this case study was conducted. Rising sea levels are forcing water lines further inland, affecting coastal rice productivity and other livelihood activities, food security and public health.

A future cyclone with a higher level of storm surge could cause saline intrusion further into the landmass, thus threatening the whole coastal region and its 33 million people. Poorer households will experience significantly greater loss and damage as a result. The study demonstrates that the extreme poor were disproportionately affected by salinity as a percentage of their income, by comparison to non-poor households. This indicates a need for a pro-poor adaptation strategy for the coastal region of the country. About one-third of people living on the coast will be badly affected. This is mainly because most of the coastal population depends on rice cultivation for their livelihoods and food security.

Poor farmers are severely affected by salinity intrusion in rice fields. Farmers and communities are trying to adapt to changing climate conditions in different ways. Some farmers are able to implement adaptation measures on their own; some are adapting with assistance from relevant government departments, non-governmental organisations and civil society forums. The government is mainly providing infrastructure and technological adaptation options for rice production.

Some saline-resistant rice cultivars, such as BRRI 23, were giving good yields until 2008. Unfortunately, BRRI 23, the variety preferred by farmers because of its quality and high yields, became ineffective with the rapid increase of salinity caused by cyclone Aila in 2009. As existing cultivars were not able to tolerate high salinity in rice fields between 2009 and 2011, new technological adaptations were needed. But in the absence of new and high salinity-resistant rice cultivars, farmers suffered huge losses, as mentioned in Section 3. After 2009, a number of new rice cultivars (BRRI 47 and BINA 8) were introduced which could resist moderate levels of salinity. However, these cultivars are for the dry season, which is not the primary rice cropping season in the study areas. This means that it is of utmost importance to develop highly resistant aman rice cultivars, although there are certainly other options. 
It is now important to rethink long-term planning for rice cultivation in the coastal zone, not only in areas currently affected by saline intrusion but also in areas that could potentially be affected, according to predicted climate scenarios. Low-lying agricultural land needs to be securely protected, while at the same time innovative and contextspecific practices, including climate-resilient rice cultivation (seeds and methods), must be researched and implemented.

It is important to highlight the problems of coastal communities experiencing saline intrusion caused by extreme events (e.g., cyclones Sidr and Aila). Households are bearing the burden of loss and damage in rice farming, and the costs of repair and reconstruction of damaged infrastructure and local facilities. Loss of productivity due to illness caused by food shortages would push these poorer groups into even greater poverty. Increasingly, people are moving from the coast, mainly because of loss of livelihood opportunities. This internal migration (rural-urban, coastal-central) will intensify as sea levels continue to rise, as extreme weather events become more frequent, and if adaptation options remain inadequate. The ultimate destination of these poor families is the urban slum. This migration caused by various climate factors including salinity intrusion will further put the capital, and other nearby cities and towns, in a challenging situation as they attempt to meet the additional needs for adequate utility and other services for old and new city dwellers.

\section{References}

Bangladesh Bureau of Statistics (2009) Yearbook of Agricultural Statistics of Bangladesh, Statistics Division, Ministry of Planning, Government of Bangladesh.

Bangladesh Bureau of Statistics (BBS) (2008) Yearbook of Agricultural Statistics of Satkhira, Statistics Division, Ministry of Planning, Dhaka, Bangladesh.

Bangladesh Bureau of Statistics (BBS) (2010) Yearbook of Agricultural Statistics of Bangladesh, Statistics Division, Ministry of Planning, Government of Bangladesh.

Banglapedia (2003) National Encyclopedia of Bangladesh, Asiatic Society of Bangladesh, Dhaka, Bangladesh.

Disaster Management Bureau (DMB) (2010) National Plan for Disaster Management 2010-2015, Disaster Management and Relief Division, Ministry of Food and Disaster Management, Dhaka, Bangladesh.

Huq, S. and Ayers, J. (2008) Climate Change Impacts and Responses in Bangladesh, Policy Department Economy and Science, European Parliament, Brussels, Belgium.

Islam, M.R. (2004) Where Land Meets the Sea: A Profile of the Coastal Zone of Bangladesh, University Press Limited, Dhaka, Bangladesh.

Loss and Damage in Vulnerable Countries Initiative, Policy Report, Report No. 9, Bonn, United Nations University Institute for Environment and Human Security (UNU-EHS).

Ministry of Environment and Forests (2005) National Adaptation Programmes of Action, Final Report, Dhaka, Bangladesh.

Rabbani, M.G., Rahman, A.A. and Islam, N. (2010) 'Climate change and sea level rise: issues and challenges for coastal communities in the Indian Ocean region', in Michel, D. and Pandya, A. (Eds.): Coastal Zone and Climate Change, pp.17-29, The Henry L Stimson Center, Washington.

Soil Resource Development Institute (SRDI) (2010) Saline Soils of Bangladesh, SRDI, Ministry of Agriculture, Dhaka, Bangladesh.

Upazilla Agriculture Office (UAO) ( 2012) Rice production Data for 1990-2011, Shyamnagar, Satkhira. 
Warner, K., van der Geest, K., Kreft, S., Huq, S., Harmeling, S., Kusters, K. and de Sherbinin, A. (2012) Evidence from the Frontlines of Climate Change: Loss and Damage to Communities Despite Coping and Adaptation.

\section{Notes}

1 The union is the lowest administrative unit.

2 Aus rice variety is planted in April and harvested in August.

3 Aman refers to rice varieties grown between June and December.

4 Boro refers to cultivation between December and May.

5 Trees that provide economic benefits to the communities, e.g., mango tree.

6 Field-based measures refer to the technology and practices that take place in the agricultural field.

$7 \quad$ Non-field-based measures refer to the options or practices that are not agricultural field-based. Non-agricultural activities are mainly included in this category of measure. 